\title{
Commentary on using equivalent latitude in the upper troposphere and lower stratosphere
}

\author{
L. L. Pan ${ }^{1}$, A. Kunz ${ }^{1, *}$, C. R. Homeyer ${ }^{2}$, L. A. Munchak ${ }^{1, * *}$, D. E. Kinnison ${ }^{1}$, and S. Tilmes ${ }^{1}$ \\ ${ }^{1}$ National Center for Atmospheric Research, Boulder, Colorado, USA \\ ${ }^{2}$ Texas A\&M University, College Station, Texas, USA \\ *now at: Forschungszentrum Jülich, Jülich, Germany \\ ${ }^{* *}$ now at: Science System Applications, Greenbelt, Maryland, USA
}

Correspondence to: L. L. Pan (liwen@ucar.edu)

Received: 10 October 2011 - Published in Atmos. Chem. Phys. Discuss.: 15 December 2011

Revised: 26 August 2012 - Accepted: 7 September 2012 - Published: 11 October 2012

\begin{abstract}
We discuss the use of potential vorticity (PV) based equivalent latitude (EqLat) and potential temperature $(\theta)$ coordinates in the upper troposphere and lower stratosphere (UTLS) for chemical transport studies. The main objective is to provide a cautionary note on using EqLat $-\theta$ coordinates for aggregating chemical tracers in the UTLS. Several examples are used to show 3-D distributions of EqLat together with chemical constituents for a range of $\theta$. We show that the use of PV- $\theta$ coordinates may not be suitable for several reasons when tropospheric processes are an important part of a study. Due to the different static stability structures between the stratosphere and troposphere, the use of $\theta$ as a vertical coordinate does not provide equal representations of the UT and LS. Since the $\theta$ surfaces in the troposphere often intersect the surface of the Earth, the $\theta$ variable does not work well distinguishing the UT from the boundary layer when used globally as a vertical coordinate. We further discuss the duality of $\mathrm{PV} / \mathrm{EqLat}$ as a tracer versus as a coordinate variable. Using an example, we show that while PV/EqLat serves well as a transport tracer in the UTLS region, it may conceal the chemical structure associated with wave breaking when used as a coordinate to average chemical tracers. Overall, when choosing these coordinates, considerations need to be made not only based on the time scale of PV being a conservative tracer, but also the specific research questions to be addressed.
\end{abstract}

\section{Introduction}

Potential vorticity (PV) based equivalent latitude (EqLat) and potential temperature $(\theta)$ are widely used in the stratospheric chemistry and dynamics community as a set of quasiLagrangian coordinates (e.g., Butchart and Remsberg, 1986; Lait et al., 1990; Randel et al., 1998; Manney et al., 1994; 1999; Pan et al., 2002; Kanzawa et al., 2003; Juckes, 2007). Because PV and $\theta$ provide a good coordinate system that approximately follows the motion of ensemble of air parcels, interpretation of tracers in this coordinate system eliminates many of the problems with assessing chemical evolution of the air mass in conventional Eulerian coordinates (Schoeberl et al., 1989). This set of coordinates has been especially effective in studies of polar stratospheric processes, because EqLat based chemical tracer analyses serve to separate dynamical variability from chemical processing, both of which contribute to the ozone budget in and around the polar vortex. The growing interest in the chemistry and dynamics of the upper troposphere and lower stratosphere (UTLS) has fostered the desire for similar quasi-Lagrangian coordinates for the tropopause region. PV based EqLat has been used in UTLS transport analyses (e.g., Haynes and Shuckburgh, 2000; Berthet et al., 2007), compiling trace gas climatologies from sparsely sampled data (e.g., Hoor et al., 2004; Engel et al., 2006; Hegglin et al., 2006) and to perform comparisons between models and observations (e.g., Strahan et al., 2007). Since PV is known as an effective tracer of stratospheric air mass, the PV based EqLat serves to obtain zonal average behaviour of the region with the air mass grouped according to dynamical conditions. 
Similar to the role of the polar vortex edge in the overworld (where the $\theta$ surfaces lie entirely in the stratosphere, Hoskins, 1991), the tropopause is a significant dynamical boundary that separates air masses of distinct chemical compositions in the middleworld (where the $\theta$ surfaces intersect the extratropical tropopause, Hoskins, 1991). The tropopause region, however, is significantly different from the polar vortex region in the behaviour of both $\mathrm{PV}$ and $\theta$. In the polar stratosphere, $\mathrm{PV}$ is a quasi-conservative dynamical variable both inside and outside of the polar vortex. This is not the case for the tropopause region when the upper troposphere is of significant interest. From the perspective of time scales involved, the dynamical variability in the polar stratosphere is largely dictated by isentropic processes with a synoptic time scale of a week to 10 days. In the UTLS region, convective processes in the time scale of a few hours can play a significant role in redistributing chemical species and diabatically modifying PV. In addition, the PV based EqLat is derived in an isentropic coordinate system. In the polar stratosphere, isentropes are quasi-lateral (i.e., approximately horizontal in Eulerian altitude sense) and serve well as vertical coordinates. In the troposphere, however, isentropes often intersect the Earth surface and at times and may have a significant vertical component in the Eulerian sense (for example, see Shapiro et al., 1999). These are perhaps the most significant distinctions between the polar vortex edge and the tropopause.

Despite these distinctions, EqLat- $\theta$ may still be a preferred coordinate system for many UTLS applications. In this note, we discuss some potential issues of using EqLat in the UTLS for chemical tracer analyses. We examine EqLat as a 3-dimensional (3-D) variable, together with chemical tracers, and $\theta$ as a vertical coordinate variable in the UTLS region in contrast to latitude and pressure/altitude coordinates to make several points. These discussions may help recognise some unintended consequences of using EqLat $-\theta$ coordinates in aggregating chemical measurements. It is not the goal of this discussion to address the general applicability of EqLat in the UTLS, but rather to note that when considering these coordinates it is important to determine whether the use of these coordinates clarifies or obscures the issues of a particular research question. The discussion should also help to consider EqLat- $\theta$ coordinates within a suite of complementary methods for aggregating data in the UTLS, including tropopause relative coordinates (Pan et al., 2004; Tilmes et al., 2010), jet stream based coordinates (Ray et al., 2004; Manney et al., 2011), and tropopause relative latitude coordinates (Kunz et al., 2011b).

One specific example is the use of PV/EqLat as a tracer versus a boundary/coordinate for zonal averaging. This is a frequently encountered issue in stratosphere-troposphere exchange (STE) studies. On the one hand, we identify stratospheric contribution to the troposphere using high PV as a signature. On the other hand, we use PV-based EqLat to aggregate trace gas species, which in effect removes the high
PV air mass from the tropospheric average. Similar situations may occur in the other direction of STE where tropospheric intrusions are observed to be associated with low PV, therefore, low EqLat (Pan et al., 2009). We use an example to show that an EqLat based zonal average conceals these events (by mapping these events based on their origin). The example raises a general question on how well EqLat climatologically separates reversible (wave) from the presence of irreversible (wave breaking) transport.

This question is particularly relevant to the ongoing studies of double tropopause phenomena. Increasing number of case studies have shown that double tropopause events in mid- to high latitudes are often signatures of poleward Rossby wave breaking and are accompanied by chemical signatures of tropospheric air mass intruding into lower stratosphere above the subtropical jet and mid-latitude tropopause (Randel et al., 2007; Pan et al., 2009; Pan et al., 2010, Homeyer et al., 2011). Statistics based on satellite observations indicate that the maximum occurrence is in late winter and early spring (Randel et al., 2007; Peevey et al., 2011). In contrast, in a Lagrangian view of the tropopause using trajectory based statistical analyses, a ventilation layer, a layer similar to the secondary tropopause in the Eulerian view, is found to be more prevalent in summer in the EqLat $\theta$ space (Berthet et al., 2007). Many factors may contribute to the apparent controversy in this case. We raise the question here whether and how much the use of EqLat versus the geographical latitude may have contributed to the differences.

This commentary is also motivated by the ongoing community activity of process-oriented chemistry climate model (CCM) evaluation with enhanced representation of both stratosphere and troposphere chemistry (http://projects. pmodwrc.ch/ccval/). One of the challenges is to integrate the research aircraft data from a large number of field campaigns over many years for model evaluation. The discussions here are relevant to the consideration of using EqLat $\theta$ coordinates to compile aircraft climatology globally.

We begin with a brief summary of the EqLat calculation, followed by a comparison of EqLat $\theta$ between the overworld polar stratosphere and the UTLS region. Then, the morphology of EqLat and chemical tracers at the middleworld isentropes, and the compactness of tracers in EqLat versus geographical latitude for the UTLS region are shown. Finally, we use an example to contrast the use of EqLat as a tracer versus a coordinate variable. Two trace gas species, ozone $\left(\mathrm{O}_{3}\right)$ and carbon monoxide (CO), are used to demonstrate the relationship between chemical trace gas and EqLat. These two chemical species are the most commonly used transport tracers in the UTLS region and one has its primary source in the stratosphere and the other in the troposphere. The chemical tracers are from the NCAR Whole Atmosphere Community Climate Model (WACCM). 
Feb 15, 2006, $380 \mathrm{~K}$

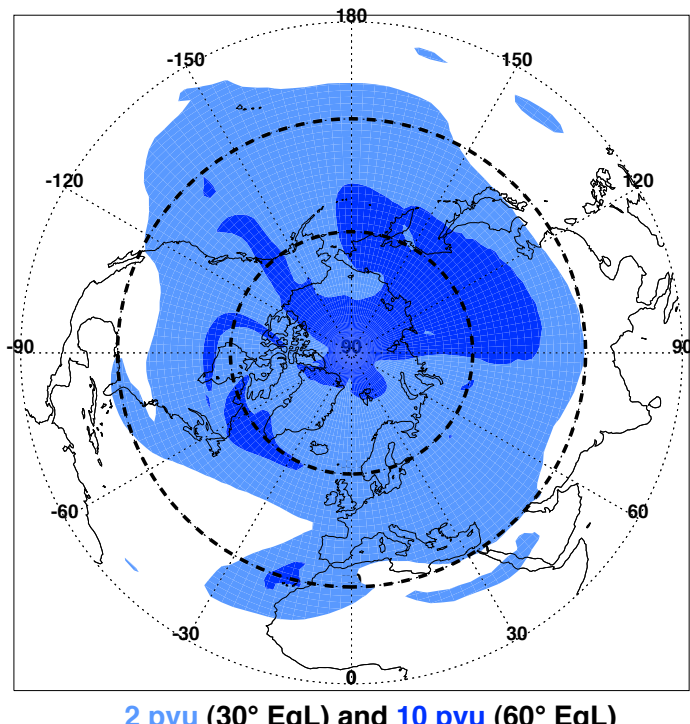

$2 \mathrm{pvu}\left(30^{\circ} \mathrm{EqL}\right)$ and $10 \mathrm{pvu}\left(60^{\circ} \mathrm{EqL}\right)$

Fig. 1. In this example, contours of $30^{\circ}$ and $60^{\circ}$ EqLat are shown on the $380 \mathrm{~K}$ potential temperature surface for the 15 February 2006 00:00 UTC WACCM analysis. These two contours correspond to $\mathrm{PV}$ of $2 \mathrm{pvu}$ and $10 \mathrm{pvu}$, respectively. For contrast, the geographical latitudes of $30^{\circ}$ and $60^{\circ}$ (dashed circles) are also given.

\section{Data, model and EqLat calculation}

\section{WACCM Model and the specified dynamics run}

For analysis of EqLat and trace gas distributions, we use global output from version 4 of the NCAR Whole Atmosphere Community Climate Model with Specified Dynamics (SD-WACCM4). WACCM uses a free-running dynamical core that is adopted from the NCAR Community Atmosphere Model (CAM) and a chemistry module that is an extension of version 3 of the Model of OZone and Related Tracers (MOZART3) (e.g., Neale et al. (2012), Kinnison et al. (2007)). In a recent validation effort, WACCM was shown to perform very well in comparisons with many other chemistry-climate models (SPARC CCMVal, 2010). For the specified dynamics (SD) run, wind and temperature fields are nudged, at each model time step, using the Goddard Earth Observing System 5 (GEOS-5) analysis. The nudging in effect allows SD-WACCM4 to perform as a chemical transport model and facilitates the comparisons with observations. A description of the SD approach is described in Lamarque et al. (2011). In this study, SD-WACCM4 is nudged with $1 \%$ of the GEOS-5 meteorological fields (e.g., temperature, zonal and meridional winds, and surface pressure) every $30 \mathrm{~min}$. Analyses are available daily at a horizontal resolution of $1.9^{\circ} \times 2.5^{\circ}$ (lat $\times$ lon), 72 pressure levels in the vertical from the surface to $\sim 80 \mathrm{~km}$, and a time resolution of $6 \mathrm{~h}$. The vertical resolution in the model decreases with height and is $\sim 1-$ $2 \mathrm{~km}$ in the UTLS.

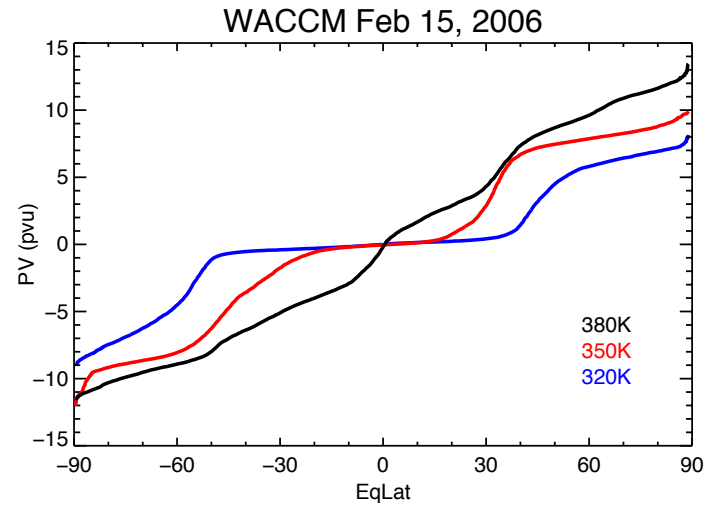

Fig. 2. The relationship of PV and EqLat for three middleworld isentropes on 15 February 2006.

\subsection{Calculation of EqLat}

Equivalent latitude maps PV to latitude based on the area enclosed by the specific isopleth of PV. For each PV value, $P_{i}$, on a given isentrope, $\theta_{j}$, there is a corresponding geographical latitude, $\phi$, the area (of the polar cap) enclosed by which equals the area $A\left(P_{i}, \theta_{j}\right)$ covered by $P>P_{i}$. This corresponding latitude is defined as the equivalent latitude for $P_{i}$ on isentrope $\theta_{j}, \phi_{e}\left(P_{i}, \theta_{j}\right)$. The above description can be written as:

$\phi_{e}\left(P_{i}, \theta_{j}\right)=\sin ^{-1}\left(1-\frac{A\left(P_{i}, \theta_{j}\right)}{2 \pi R^{2}}\right)$

where $R$ is the radius of Earth. In our calculation, the area enclosed by a given PV isopleth is calculated by summing the equivalent areas of each grid cell that has $P \geq P_{i}$.

To give an example of EqLat as an alternative representation of PV and how it compares to geographic latitude, we show in Fig. 1 areas enclosed by two selected PV contours on the $380 \mathrm{~K} \theta$ surface on 15 February 2006 . They are approximately $2 \mathrm{pvu}$ and $10 \mathrm{pvu}$, and correspond to $30^{\circ}$ and $60^{\circ}$ EqLat, respectively. In contrast to $30^{\circ}$ and $60^{\circ}$ geographic latitude circles, the EqLat field embodies the instantaneous PV field and provides a snapshot of the underlying conservative dynamics.

Figure 2 shows the one-to-one relationship between PV and EqLat at three middleworld q-levels (320, 350 and $380 \mathrm{~K})$. This figure highlights that the re-mapping of PV to EqLat is nonlinear. On the two lowest middleworld isentropes, large gradients of PV as a function of EqLat are concentrated in the mid-equivalent latitudes, i.e., near the strongest jet stream. These regions of strong gradient are in fact the locations of the tropopause (Kunz et al., 2011a). Away from these regions, both equatorward and poleward, $\mathrm{PV}$ is nearly homogenous and is a weak function of EqLat. The implication of this behaviour to chemical tracer averaging will be discussed in later examples. 
Feb 15, 2006 WACCM 600K
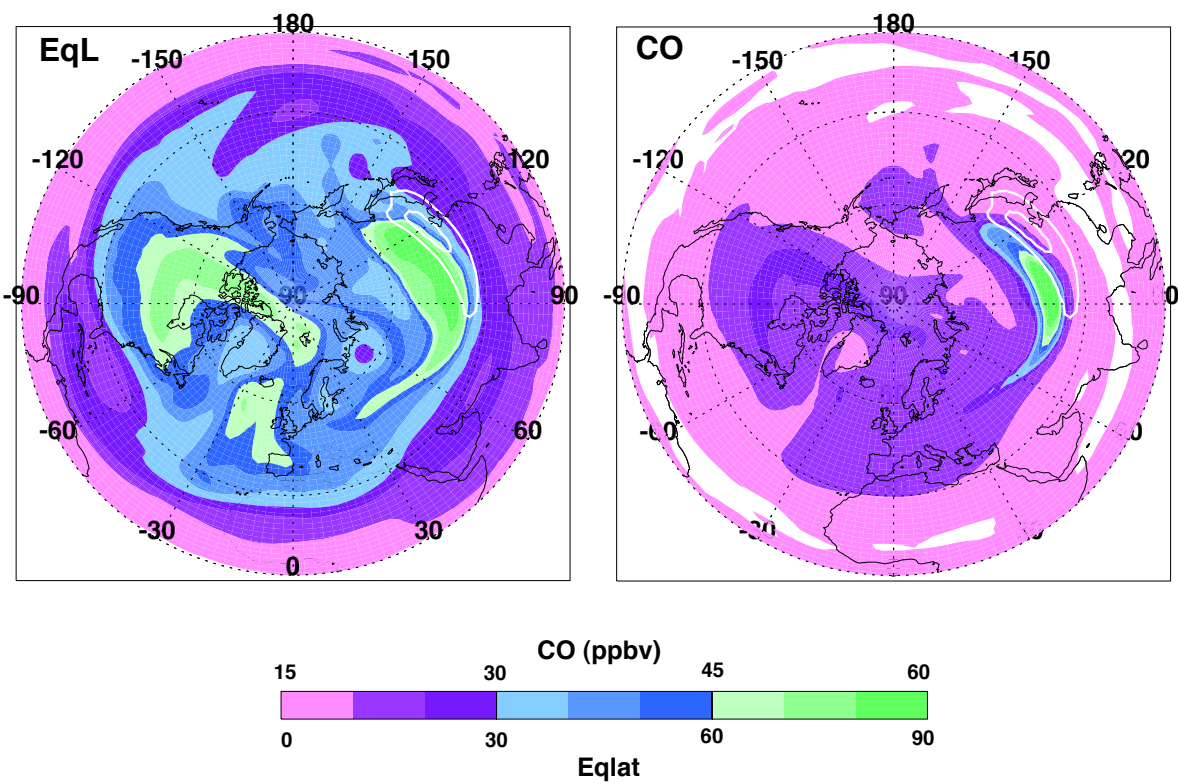

Fig. 3. Distribution of EqLat (left) and CO (right) on the $600 \mathrm{~K}$ isentropic surface. The white contours represent 30 and $40 \mathrm{~m} \mathrm{~s}^{-1}$ wind speeds.

Feb 15, 2006 WACCM 600K
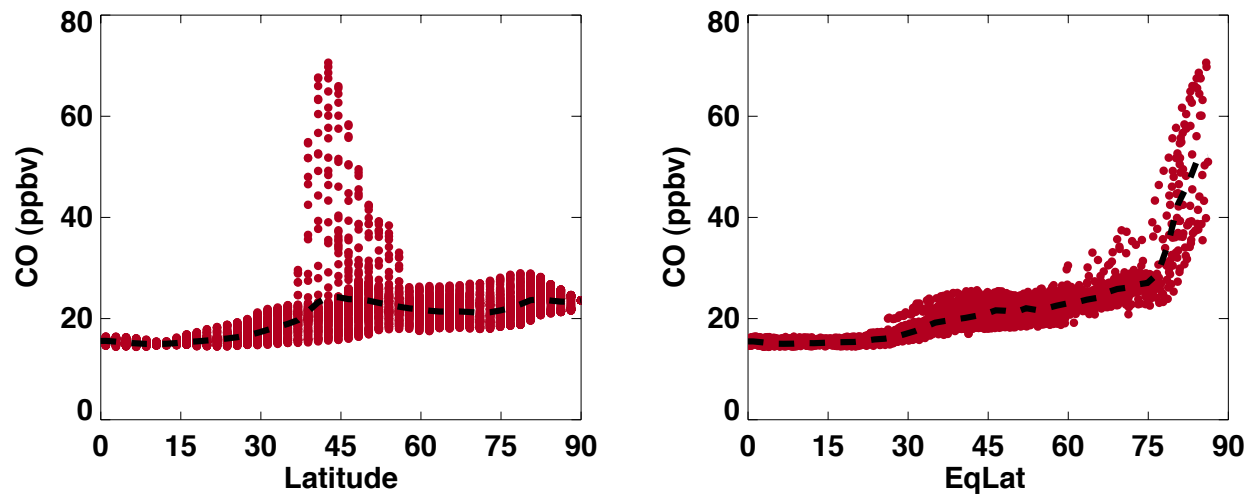

Fig. 4. Scatterplots of WACCM CO at $600 \mathrm{~K}$ as functions of latitude (left) and equivalent latitude (right). The black dashed lines represent the zonal means (calculated in $1.9^{\circ}$ intervals) in latitude or EqLat coordinates, respectively.

\section{EqLat in the polar stratosphere}

Trace gas distributions in the winter stratosphere are strongly influenced by vortex dynamics, and consideration of the vortex is essential when aggregating trace gas data. Figures 3 and 4 demonstrate how EqLat can be used to produce dynamically consistent averages of trace gas distributions. Figure 3 shows EqLat and CO mixing ratio from the WACCM model in the Northern Hemisphere (NH) on the $600 \mathrm{~K} \theta$ surface on 15 February 2006. In this case, following a major stratosphere sudden warming (Coy et al., 2009) the air mass associated with the polar vortex is fragmented into three pieces (green shading). The piece containing highest EqLat is lo- cated near $45^{\circ} \mathrm{N}$ and $90^{\circ}-120^{\circ} \mathrm{E}$. There are corresponding signatures in the $\mathrm{CO}$ field. This well-known correlation is produced by the descent of polar vortex air that brings higher $\mathrm{CO}$ produced by $\mathrm{CO}_{2}$ photolysis in the mesosphere and lower thermosphere into the stratosphere (Allen et al., 1999).

Figure 4 compares scatterplots and averages of $\mathrm{CO}$ mixing ratio using the geographical latitude with that using EqLat. In geographical latitude coordinates, the vortex fragment with high $\mathrm{CO}$ near $45^{\circ} \mathrm{N}$ is averaged with low-CO air from outside the vortex to produce a small peak in zonal-mean $\mathrm{CO}$ near $45^{\circ} \mathrm{N}$. The zonal-mean $\mathrm{CO}$ across all latitudes is nearly flat at around $20 \mathrm{ppbv}$. Averaging in EqLat-coordinates produces a very different picture, with $\mathrm{CO}$ enhanced by up to 


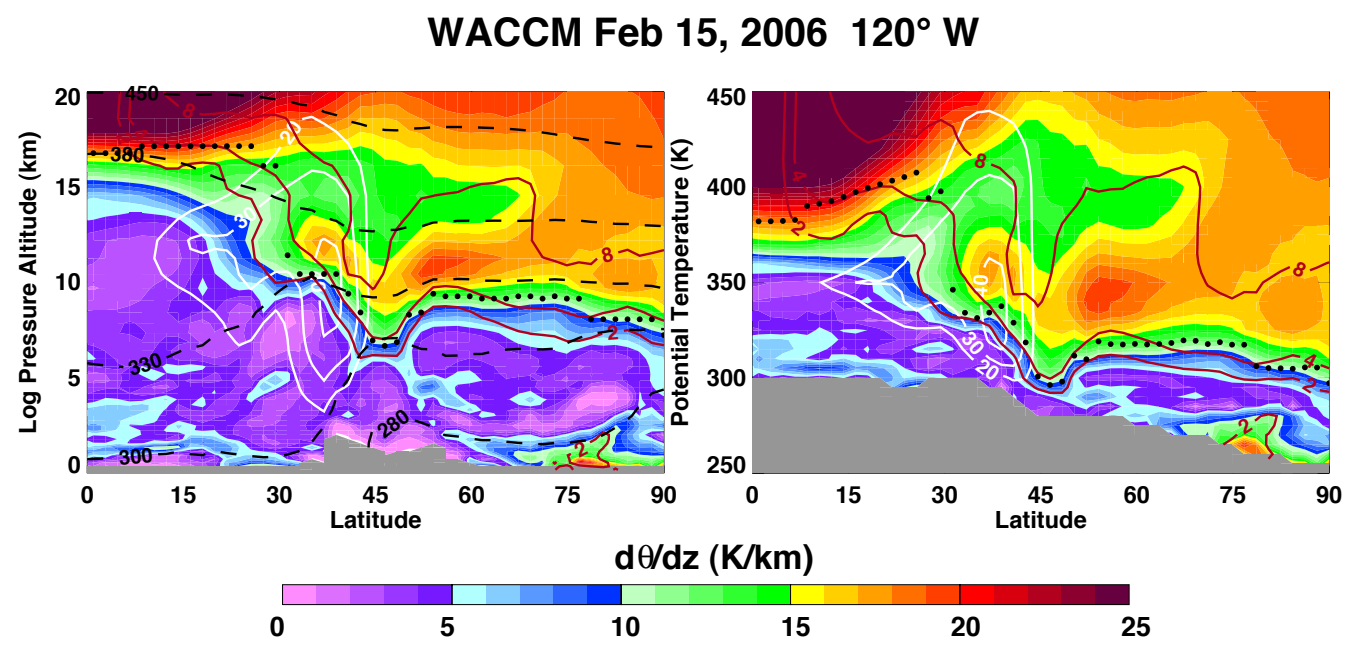

Fig. 5. An example of a latitude-height cross-section in Log-pressure altitude (left) versus potential temperature (right) coordinates. Colour images represent static stability (potential temperature lapse rate). Also shown are zonal wind speed ( $\mathrm{m} \mathrm{s}^{-1}$, white lines), PV (red lines) and the thermal tropopause (black dots). The cross-sections are along $120^{\circ} \mathrm{W}$ longitude. In the $\theta$-coordinate the troposphere is a narrow layer, especially around the subtropical jet.

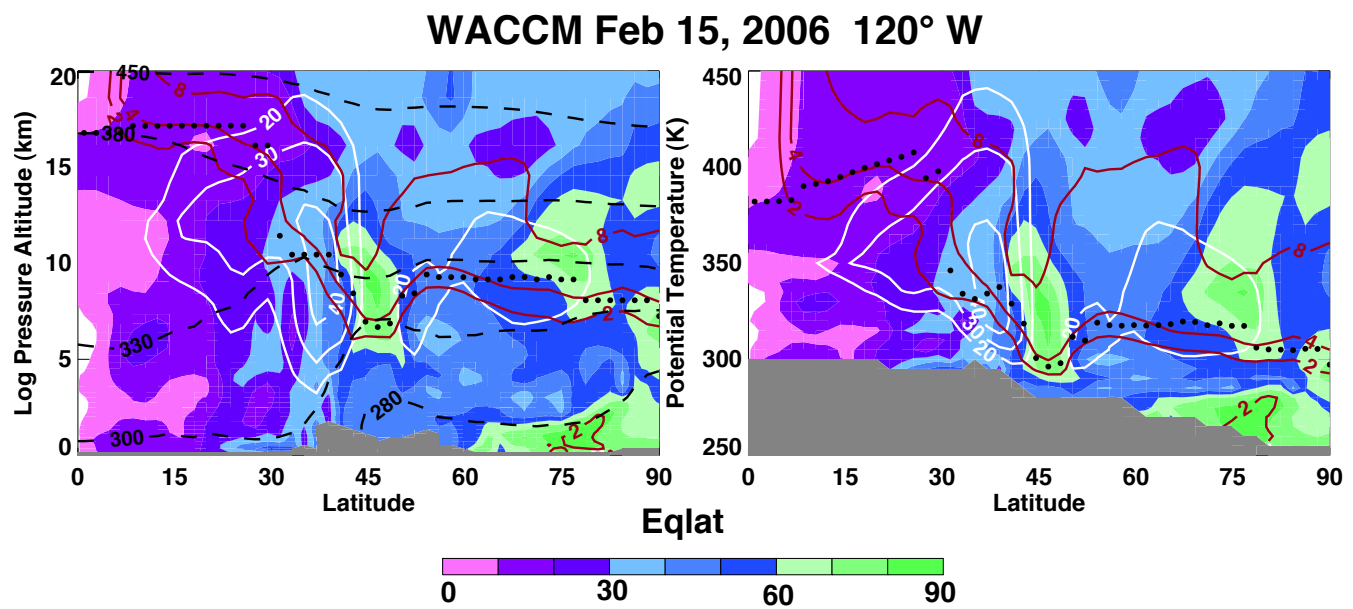

Fig. 6. As in Fig. 5 but for EqLat.

$50 \mathrm{ppbv}$ in the vortex (poleward of $75^{\circ} \mathrm{N}$ in EqLat). This example demonstrates the utility of EqLat-coordinates in the polar stratosphere: these coordinates highlight the association of large $\mathrm{CO}$ abundance with polar vortex air, which is lost when viewed as function of geographical latitude.

\section{EqLat and $\theta$ in the UTLS}

In contrast to the overworld, the representation of UTLS in the EqLat $\theta$ coordinates requires some additional considerations. While isentropes are quasi-horizontal in the stratosphere, they often have a significant vertical component in the troposphere, i.e., $\theta$ surfaces may span the upper troposphere and the boundary layer or intersect the Earth surface. An example can be seen in Fig. 5, where the $300 \mathrm{~K}$ poten- tial temperature contour represents the upper troposphere in mid to high latitudes, but boundary layer in the low latitudes. From a slightly different perspective, the stratosphere is stable and stratified because of the large vertical gradient in $\theta$, i.e., high static stability. The troposphere is relatively unstable and has a weak $\theta$ gradient. These simple facts reflect the nature of these two atmospheric layers so named. As a consequence, in comparison to geometric or pressure coordinates, $\theta$-coordinates expand the LS and compress the UT. This feature is illustrated in Figs. 5 and 6.

Figure 5 shows a vertical cross-section of static stability for 15 February 2006 along $120^{\circ} \mathrm{W}$ longitude. Also shown are the lapse-rate tropopause, the jet positions and selected $\mathrm{PV}$ isopleths. The two panels contrast the representation of vertical range from the ground to $20 \mathrm{~km}$ or $450 \mathrm{~K}$ in log-pressure altitude (left) and potential temperature (right) 

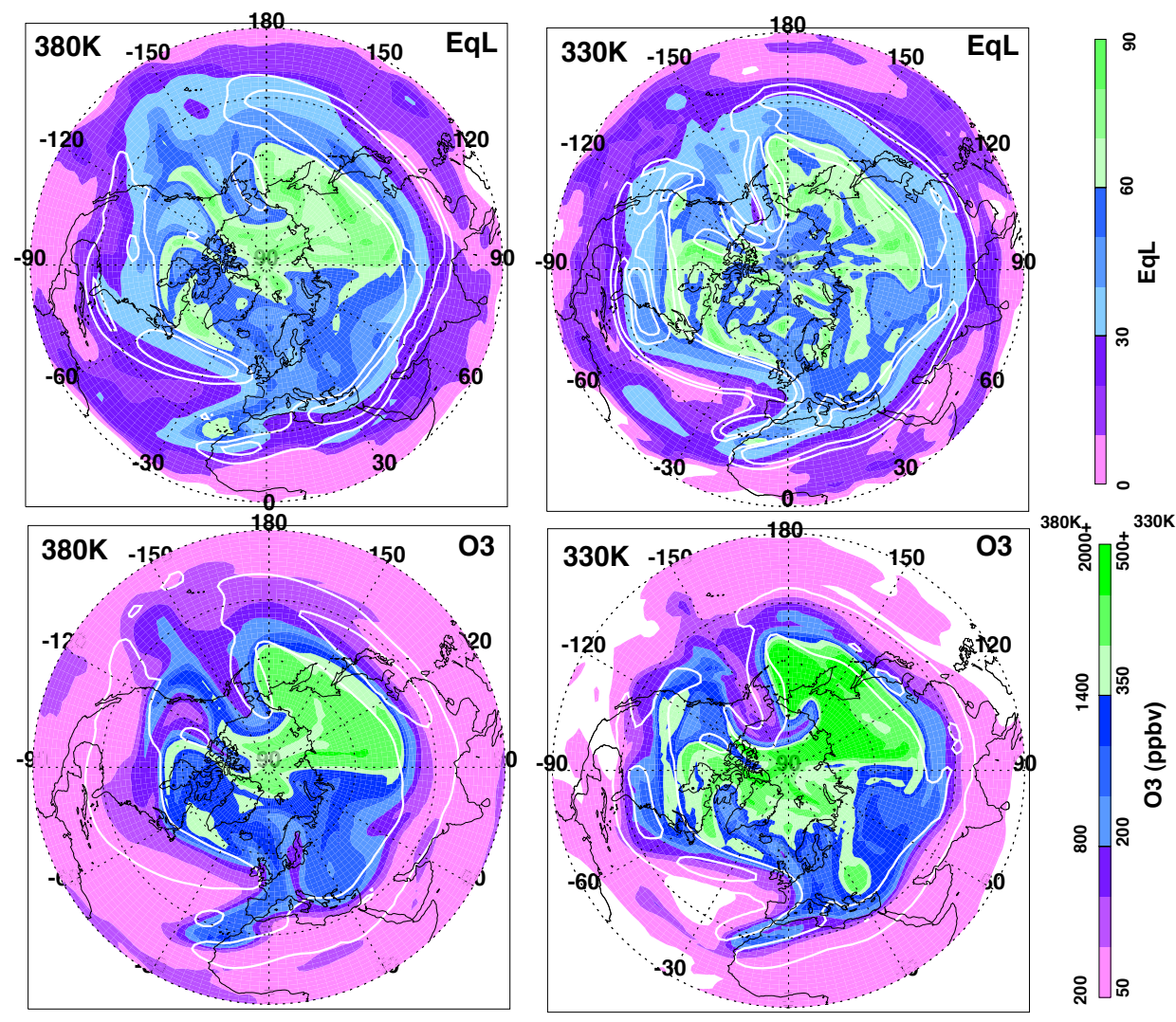

Fig. 7. WACCM EqLat and $\mathrm{O}_{3}$ on the $380 \mathrm{~K}$ (left column) and $330 \mathrm{~K}$ (right column) $\theta$-surfaces for 15 February 2006 . The position of the jet is represented by white contours (wind speeds of 30 and $40 \mathrm{~m} \mathrm{~s}^{-1}$ ).

vertical coordinates. The two scales represent a similar vertical range. The main message of the figure is that in altitude space, the tropopause divides the lower stratosphere and troposphere roughly equally in terms of the area in the cross-section. In $\theta$ space, on the other hand, the asymmetry is quite obvious with the entire troposphere reduced to a narrow layer. The relevance of this information is that often times when potential temperature is used as the vertical coordinate, a layer of $20-30 \mathrm{~K}$ above the tropopause is contrasted to a layer of $20-30 \mathrm{~K}$ below the tropopause. We want to point out here that, the former is a narrow layer of $1-2 \mathrm{~km}$ in the geophysical space and only represents the bottom of the stratosphere, while the latter is often the entire troposphere. One needs to be aware of this asymmetry when using isentropic coordinates in the UTLS.

Figure 6 shows a cross-section of EqLat as a 3-D variable, together with the tropopause and the jet locations, in both Log-pressure altitude and potential temperature vertical coordinates. In addition to showing the asymmetry of representing UT versus LS, the comparison of the wind and EqLat distribution highlights the role of the jet streams in the UTLS EqLat distribution. In the subtropics, the quasivertical isolines of EqLat are approximately perpendicular to and increase with latitudes across the strong subtropical jet, an indication that EqLat here serves well as a latitudinal coordinate variable. It is evident, in this example, how the jet structure is dominating the latitudinal PV variation. The high $\mathrm{PV}$ and associated high EqLat around the jets is accompanied by lower EqLat away from the jets, where the PV isolines are quasi-lateral and largely parallel to the isentropes. The weak gradient in PV-EqLat relationship away from the strong jet, as shown in Fig. 2, is responsible for this structure. This structure raises the question whether the behaviour is consistent with the UTLS chemical distribution and what implications are when using the coordinates for averaging chemical tracers. This is the focus of the next section.

\section{EqLat and chemical tracers in the UTLS}

Although it is well known that PV is not a conservative tracer in the troposphere, PV based EqLat is often used to create zonal averages for aircraft data including both stratosphere and troposphere. In most cases, the studies are mainly focused on stratospheric processes and the inclusion of the troposphere is only to show the range of sampling (e.g., Hoor et al., 2004; Hegglin et al., 2006; Engel et al., 2006). With an ongoing community effort of enhancing the representation of 
stratosphere and troposphere chemistry in the new generation of CCMs, there is a need to identify an optimal method of aggregating research aircraft data, which often include both the troposphere and the lower stratosphere, for process oriented model evaluations. One question we consider here is to what extent EqLat $-\theta$ coordinates could serve the need and what would be unintended effects when both the stratosphere and the troposphere are included.

To provide a perspective, we show $\mathrm{O}_{3}$ and $\mathrm{CO}$ from the WACCM model for selected isentropes and in vertical crosssections. Note that these two species are the most commonly used stratospheric and tropospheric tracers, respectively, for transport studies in the UTLS region. They have very different relationships with EqLat. $\mathrm{O}_{3}$, similar to $\mathrm{PV}$, has strong stratospheric sources and is known to correlate with PV in the tropopause region (e.g., Danielsen, 1968; Browell et al., 1987; Pittman et al., 2009). CO on the other hand, has large anthropogenic origin and the surface value of $\mathrm{CO}$ has a strong relationship with geographical latitude (e.g., Novelli et al., 2003). Low CO air mass near the tropopause is often correlated with stratospheric influence. High CO air mass in the UT, on the other hand, may be an indication of convective transport or biomass burning, processes that are PV nonconservative. Figures 7-9 in this section aim to illustrate the behaviours of EqLat and tracers on several UTLS isentropes to shed light on the use of EqLat for aggregating chemical tracer data in this region.

Figure 7 shows a $\mathrm{NH}$ view of EqLat and $\mathrm{O}_{3}$ distributions on two selected isentropes ( $380 \mathrm{~K}$ and $330 \mathrm{~K}$ ). On the $380 \mathrm{~K}$ surface, the spatial patterns of EqLat and $\mathrm{O}_{3}$ are largely consistent. This is especially true for high EqLat and high $\mathrm{O}_{3}$ and the gradient change in the region of the jet stream. The $380 \mathrm{~K}$ level is largely stratospheric, as indicated by Figures 5-6. This is no longer the case at $330 \mathrm{~K}$, a level that spans the middle troposphere in the tropics, the tropopause region in the mid-latitudes and the lower stratosphere in the high latitudes. At this level, the high (polar) EqLats are shown to be strongly associated with the jet streams. The gradients of tracer distribution in the subtropics show a good consistency with the gradient of EqLat but lose correlation at high latitudes. If the $\mathrm{O}_{3}$ field is re-sampled using EqLat, the dynamical variability in the subtropics and mid-latitudes will be mapped consistently with the dynamical field. However, $\mathrm{O}_{3}$ in the polar region will be mapped into mid-equivalent latitudes. What produced this large difference between the EqLat and $\mathrm{O}_{3}$ in the polar latitudes is not entirely understood. In addition to the known weak gradient (Fig. 2), we speculate that this relationship may be dependent on the seasonality of static stability in the polar UTLS, which reaches a minimum that is less than that in mid-latitudes during winter in each hemisphere (e.g., Tomikawa et al., 2009; Grise et al., 2010). This lack of compact tracer-EqLat correlation away from the tropopause (or jet) region is also seen in the scatterplot (Fig. 9).
WACCM Feb 15, 2006 Lon=0.
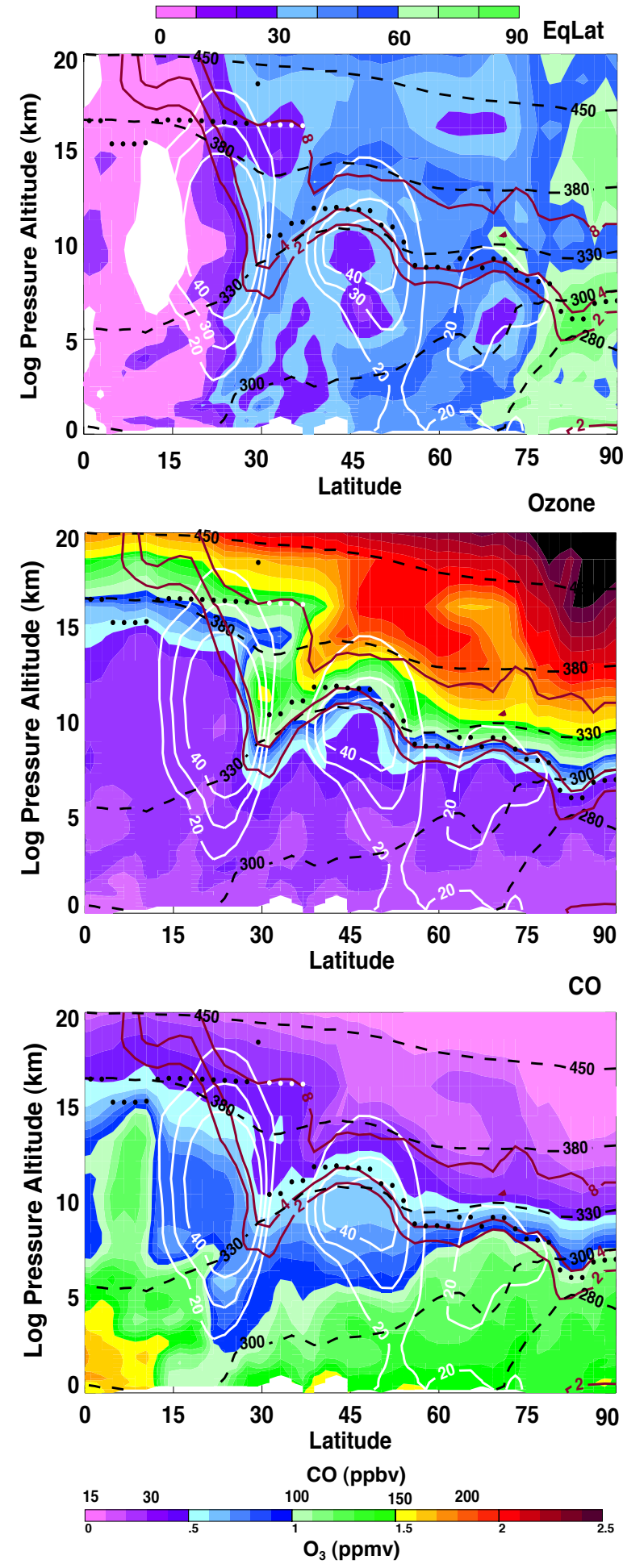

Fig. 8. WACCM NH meridional cross-sections of EqLat (top), Ozone (middle) and CO (bottom) for 15 February 2006 along $0^{\circ}$ longitude. In each panel, selected meteorological variables are also shown, including isentropes (black dash lines), wind speed (white lines), PV (red lines) and the thermal tropopause (black dots). White colour-filled areas of EqLat represent negative values. 


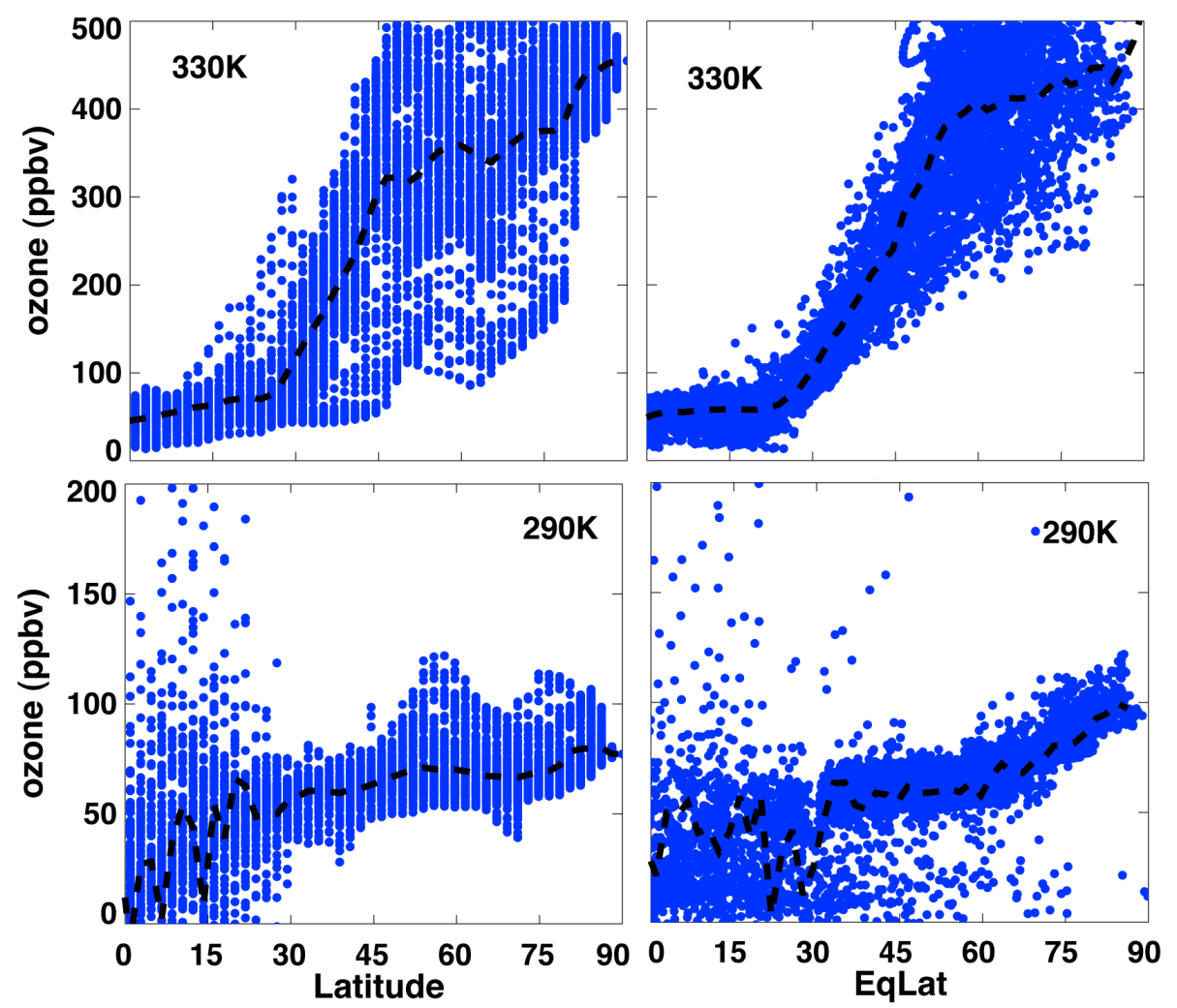

Fig. 9. WACCM NH ozone as a function of latitude (left) and EqLat (right) for the $330 \mathrm{~K}$ and $290 \mathrm{~K}$ potential temperature surfaces on 15 February 2006. The dashed line in each plot represents the zonal average in their respective coordinates.

Figure 8 provides a cross-section view of EqLat and chemical tracers in the UTLS region to complement the view on $\theta$-surfaces in the previous figure. Overall, the figure highlights the strong vertical gradients in the tracer cross-section, and the role of the tropopause in dictating the change in the tracer fields. In this particular cross-section, three upper tropospheric jet streams, the subtropical, the polar and the Arctic jets, are clearly identifiable in the wind fields. In the region of the subtropical jet between $5-15 \mathrm{~km}$, the horizontal gradients of the tracers are consistent with the gradients of EqLat. Away from the subtropical jet, and the variable EqLat shows weakened latitudinal gradient which is consistent with the PV-EqLat relationship shown in Fig. 2. This figure suggests that while EqLat maybe effective in the subtropics, away from the subtropical jet tropopause relative coordinates are more effective in representing the variability of the tracers.

Note that in the tropics (equatorward of the subtropical jet), there is a region of strong enhancement of $\mathrm{CO}$, likely representing the influence of convective transport coupled with local emission sources. This region is associated with negative EqLat, consistent with the likely convective modification of PV. Although this behaviour is well known, this example illustrates how the use of EqLat as a global coordinate may result in undesired tracer redistributions. In this case the
CO plum will be mapped to the Southern Hemisphere in an EqLat based zonal average.

Figure 9 shows scatterplots of $\mathrm{O}_{3}$ as a function of latitude and EqLat and their respective zonal averages for the $330 \mathrm{~K}$ and $290 \mathrm{~K}$ levels. The two levels are chosen to contrast LS and UT for mid- to high latitudes, and also to contrast the use of EqLat in the tropopause region with that in the polar stratosphere as shown in Fig. 4. At the $330 \mathrm{~K}$ level, the compactness and zonal averages using the two latitude coordinates are significantly different. The large scatter of $\mathrm{O}_{3}$ in latitude reflects the latitudinal variation of the tropopause. The distribution in the EqLat coordinate is much more compact especially in the tropopause region $\left(\sim 30^{\circ} \mathrm{N}\right.$ EqLat and 100-200 ppbv of ozone). In the polar latitudes, the correlation is no longer as compact, which is consistent with the discussion of the plane view shown in Fig. 7. Nevertheless, the figure indicates that the EqLat based average provides a better consistency with the dynamical background. In contrast, at the $290 \mathrm{~K}$ level (nearly entirely in the troposphere) both tropospheric chemistry and STE influence the $\mathrm{O}_{3}$ distribution. The low $\mathrm{O}_{3}$ scatters in the tropics (the points below $50 \mathrm{ppbv}$, for example) are mapped into high EqLat, likely due to the diabatically generated PV at this level. In this case, $290 \mathrm{~K}$ is part of the upper troposphere at high latitudes, but often part of the boundary layer at mid- to low latitudes. This 
Apr 16, 2008, $380 \mathrm{~K}$
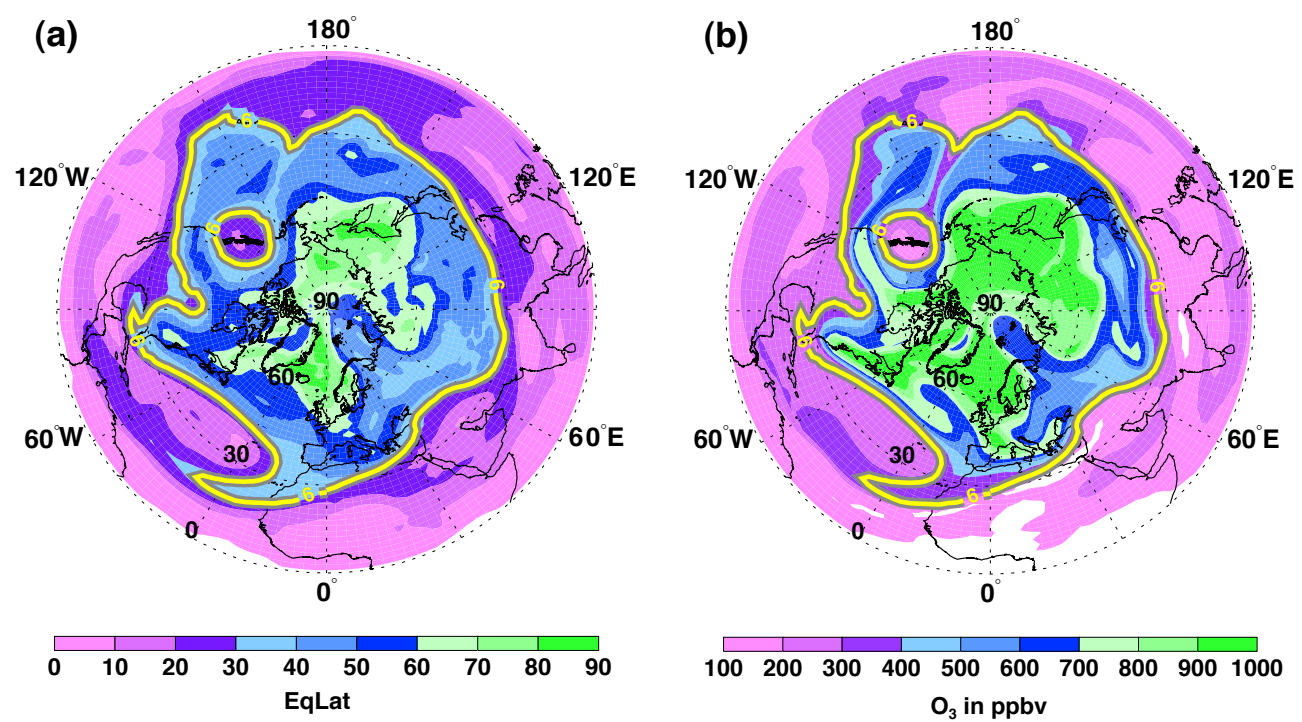

Fig. 10. Maps of (a) EqLat and (b) ozone from the SD-WACCM run for 16 April 2008 at the $380 \mathrm{~K}$ potential temperature surface. The 6 pvu PV contours are shown by the yellow lines. The dynamical tropopause is defined as the pole-enclosing 6 pvu contour.

figure illustrates that the steep slopes of the isentropes in the troposphere makes it difficult to separate UT from the boundary layer in $\theta$ coordinates. In addition, it is more important to have the geographical latitude information when it comes to identifying the source and sink origin in the lower troposphere.

\section{EqLat as a tracer versus as a coordinate variable}

An important issue to consider when using EqLat is what scientific question we intend to address. Two scenarios we contrast in this section are using EqLat as a tracer to identify the transport origins versus as a coordinate for achieving a zonal average.

Similar to the polar stratospheric studies, EqLat has been shown as an effective transport tracer in the UTLS. For example, several recent studies have shown that PV based EqLat is effective at identifying poleward intrusions of tropospheric air mass into lower stratosphere above the subtropical jet core (Pan et al., 2009; Homeyer et al., 2011). We use an example here to illustrate what happens in a tropospheric intrusion case if EqLat is used as a coordinate variable. This example is an event involving transport of tropospheric air into the lower stratosphere due to Rossby wave breaking, on April 16, 2008. A later stage of the event was sampled in situ by research aircraft during the START08 experiment (Pan et al., 2010). This wave breaking event and associated irreversible transport has been analysed in detail (Homeyer et al., 2011). We illustrate the issues here using the SD-WACCM simulation of this time period.
Figure 10 shows $380 \mathrm{~K} \mathrm{NH} \mathrm{EqLat} \mathrm{and} \mathrm{O}_{3}$ fields on 16 April 2008 from the SD-WACCM run. The 6 pvu PV contours are superimposed on each map. There are multiple contours, but only the one that encloses the pole represents the dynamic tropopause for this isentrope, determined using the PV gradient-based definition described in Kunz et al. (2011a). The tropospheric intrusion air mass is seen as a "blob" of low EqLat $\left(\sim 20^{\circ}-30^{\circ}\right)$ and low $\mathrm{O}_{3}(\sim 100-$ $200 \mathrm{ppbv}$ ) air, near $60^{\circ} \mathrm{N}$ and $140^{\circ} \mathrm{W}$, separated from the tropical reservoir. This air mass, enclosed by the shorter one of the 6 pvu contours, highlights the fact that this is, both dynamically and chemically, a bulk of tropospheric air that has been cut-off from the troposphere and is embedded in the stratospheric background. The high consistency of EqLat and $\mathrm{O}_{3}$ indicates that the low $\mathrm{O}_{3}$ is not produced chemically, but a result of transport. The figure, therefore, speaks for the effective role of EqLat as a transport tracer. In this case, the occurrence of wave breaking is signified by the PV/EqLat structure, and the process as a whole is irreversible in general (McIntyre and Palmer, 1983). Although in this case, mixing and irreversible transport associated with this event is confirmed by the in situ tracer measurement (Homeyer et al., 2011), the general quantification of air mass irreversible transport involved in this type of events is a subject of future studies (e.g., Homeyer and Bowman, 2012).

Figures 11-12 contrast the use of latitude and EqLat as the coordinate variable to compute a zonal average in this case, using data from the meridional section over the longitude range $110^{\circ}-150^{\circ} \mathrm{W}$. Figure 11 shows the $\mathrm{O}_{3}$ distribution in an isentropic dynamical tropopause relative coordinate, both in latitude and EqLat, for the $380 \mathrm{~K}$ level. In both 

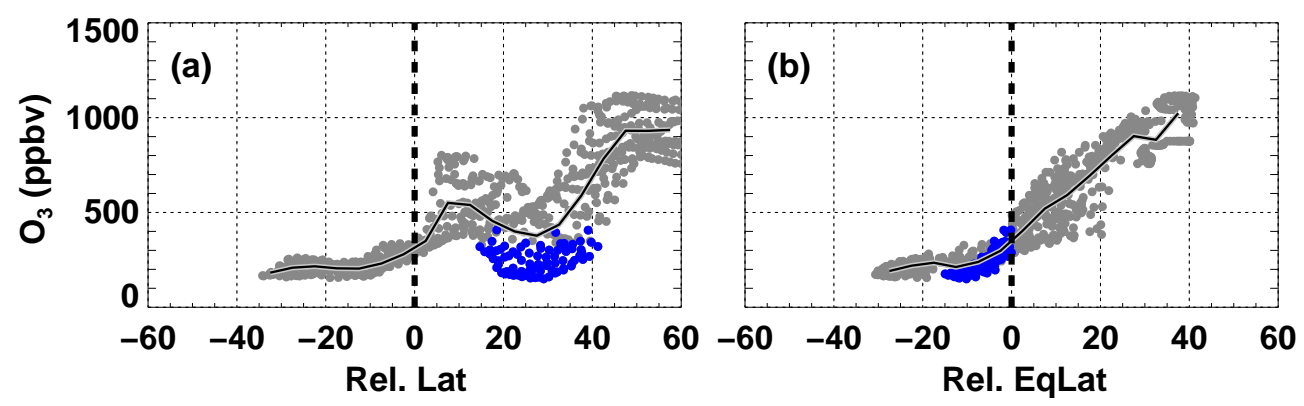

Fig. 11. Ozone at $380 \mathrm{~K}$ and from $110^{\circ}-150^{\circ} \mathrm{W}$ in longitude on 16 April 2008 , (a) as a function of relative latitude to the $380 \mathrm{~K}$ dynamical tropopause (6 pvu in Fig. 10), and (b) as a function of relative EqLat to the dynamical tropopause. The blue points highlight the parcels that are on different sides of the tropopause when using relative latitude versus relative EqLat.

\section{Apr 16, 2008, $110-150^{\circ}$ W Sectional Zonal Mean}
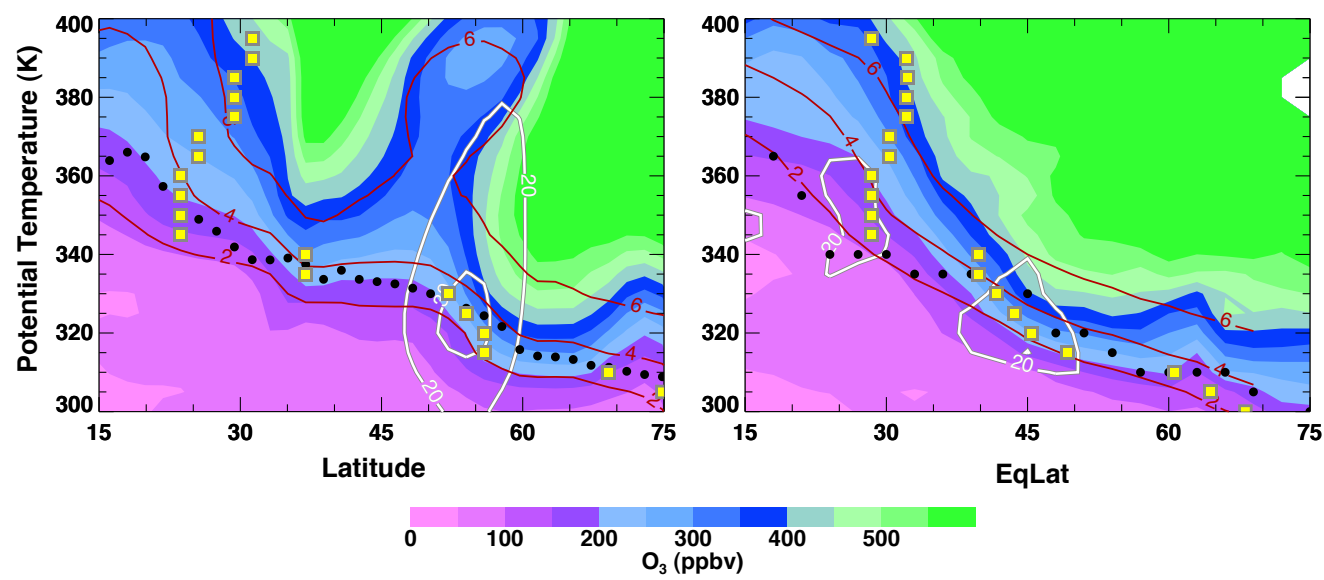

Fig. 12. Sectional zonal means of ozone for $110^{\circ}-150^{\circ} \mathrm{W}$ in (a) latitude and (b) EqLat. Yellow squares represent the dynamical tropopause at each isentrope. Black dots represent the thermal tropopause. Also shown are PV in pvu (red contours) and zonal wind in $\mathrm{ms} \mathrm{s}^{-1}$ (white contours).

cases, the zero represents the latitude or EqLat location of the isentropic tropopause (the pole-enclosing 6 pvu contour in this case). In each case, the blue points are those to be mapped to the opposite side of the tropopause depending on the coordinate variable used (relative latitude or EqLat).

As shown in Fig. 11a and b, the $\mathrm{O}_{3}$-EqLat relationship is much more compact than $\mathrm{O}_{3}$-latitude, which reflects the strong correlation of $\mathrm{O}_{3}$ and $\mathrm{PV}$ in this region and speaks to the role of transport in the ozone distribution at this $\theta$ level. The low ozone points (blue) on the positive side of the $\mathrm{O}_{3}$ relative latitude relationship, however, highlights the fact that significant transport of low ozone air mass from troposphere to stratosphere would be classified back to their transport origin if EqLat is used for zonal averaging. This issue is further highlighted in Fig. 12, where the sectional zonal mean for the region shows the low ozone air mass due to the transport latitude based zonal average. On the other hand, this low ozone air mass is mapped back to the troposphere in EqLat based zonal mean.
There exist two different views on which zonal average is more meaningful and appropriate. On the one hand, the low ozone structure associated with transport is potentially reversible since the dynamical property of the air mass is still tropospheric. If the intention is to create an average based on the dynamical property of the air mass, the use of EqLat coordinates will produce the intended average. On the other hand, if the chemical transport structures associated with the wave breaking is of interest, one needs to be aware that the use of EqLat will conceal these structures. We highlight here that the choice should be made based on the scientific question of interest. In polar vortex studies, more often the interest is to quantify the chemical evolution of the air mass in the vortex. In that case, removing the transport influence, regardless if it is reversible, by using EqLat serves the right purpose. For UTLS tracer studies, very often the goal is to quantify the transport due to STE or to characterise the dynamical variability in chemical fields. Using EqLat in this case will map the transported air mass away from the region of interest and defeat the purpose of the study, as shown in this example. 
To further clarify the issues of how we consistently characterise the dynamical variability of the chemical field in the UTLS, we connect our discussion here to a body of research that uses the PV field to characterise Rossby wave breaking in the context of STE. A few good representatives of the research are Postel and Hitchman (1999), Wernli and Sprenger (2007) and Sprenger et al. (2007). These works are based on the concept that wave breaking events are fundamentally an irreversible process and highly relevant to STE (McIntyer and Palmer, 1983). The result of these works largely represents our knowledge of preferred locations of STE. Sprenger et al. (2007), in particular, did a detailed analysis to compare PV structures (streamers, cutoffs) and STE studies from an earlier work (Sprenger and Wernli, 2003). The result shows that the PV structures do have a significant connection with the trajectory analyses based STE events, i.e., these PV structures represent STE activities. If we average the chemical tracers based on their PV or EqLat, the STE events related to these PV structures will be largely concealed. What coordinates we use to perform averaging will potentially alter the picture of spatial and seasonal variability of these STE relevant activities. The choice of coordinates, therefore, should be carefully made based on the purpose of averaging.

This example also has a specific implication in regard to the double tropopause statistics. As shown in the example, the wave breaking and associated double tropopause occurrence in this case will be concealed in the EqLat coordinate.

\section{Summary}

We have discussed three areas of concerns for using EqLat$\theta$ coordinates in the UTLS region. The first one concerns the representation of troposphere in the EqLat $\theta$ space. The EqLat $-\theta$ coordinates are fundamentally stratosphere focused (Fig. 5) and do not represent UT and LS equally. This point is relevant when tropospheric sources, sinks and processes are important to a particular study. In the subtropics, the steep slopes of the isentropes makes it difficult to use $\theta$ as a vertical coordinate globally with a clear distinction between the upper troposphere and the boundary layer. While the chemical composition in the UT is strongly coupled dynamically to the LS, the vertical transport of tracers from the boundary layer is also important. The tropospheric tracer distribution is, therefore, often strongly coupled to the surface source, which makes geographical latitude a more relevant coordinate variable.

The second area concerns the use of EqLat to aggregate chemical tracers in the region away from the jet stream. Using modelled tracers of $\mathrm{O}_{3}$ and $\mathrm{CO}$, we show examples of the polar region being mapped to middle EqLats (Fig. 6) and the possibility of convectively influenced tropical upper troposphere being mapped to the south of the Equator (Fig. 8).
Most importantly, in the third area, EqLat based zonal averages may conceal the chemical structure associated with wave breaking as shown in the last example (Figs. 10-12). Since the PV structure based Rossby wave breaking analysis is a significant part of the STE studies (e.g., Postel and Hitchman, 1999; Wernli and Spenger, 2007; and Sprenger et al., 2007), it is important to be aware that using PV as a coordinate will in effect obscure the dynamical variability of the trace gas associated with wave breaking. Whether the latitude or EqLat representation of wave breaking events has contributed to the differences in double tropopause studies should be examined in future work.

An important message that comes out of these examples is that the choice of coordinate for averaging data in this region depends on the specific scientific question. Different from the stratospheric polar vortex studies, where quantifying chemical processing in the polar vortex air is usually the goal, the focus of the UTLS region is most often to quantify transport and exchange. Intrusions from stratosphere into troposphere, and vice versa, are processes that often involve both reversible and irreversible transport and are, therefore, important STE activities to characterise in this region. Using a tracer that itself is influenced by the transport as a coordinate often convolutes the problem. A general interest of aggregating UTLS observations is also to identify transport boundaries and pathways associated with the meteorological patterns. It is often more effective to examine the chemical and dynamical tracers in parallel (Kunz et al., 2011b).

More investigations are desirable to identify the most effective coordinates for aggregating sparsely sampled data for model-observation comparisons, and for characterising UTLS transport. Studies have shown that tropopause relative coordinates work well to bring out the sharp chemical discontinuity across the tropopause (Pan et al., 2004; Tilmes et al., 2010). This method, however, is a one-dimensional averaging in the vertical, i.e., altitudinal, space. A similar approach for the horizontal dimension uses jet core relative wind speed as a coordinate for averaging in situ measurements (Ray et al., 2004), and it has shown to be effective for data analyses around the jet stream. This method, however, is limited to the regional scale. An extension of this method to the global scale, as recently proposed by Manney et al. (2011), combines the jet core relative latitudes in the horizontal dimension and the tropopause relative altitude in the vertical dimension. In a recent study, isentropic chemical gradient and PV gradients are examined together. The results show that the PV gradient based tropopause captures the chemical change well in general, and a relative latitude coordinate, similar to the relative altitude coordinate in the vertical dimension, can be used for aggregating data and making zonal averages (Kunz et al., 2011b). Well designed case studies comparing these different approaches with the EqLat- $\theta$ based zonal averages may help to identify the strengths and weaknesses of these different methods. 
Acknowledgements. The National Center for Atmospheric Research is sponsored by the National Science Foundation. The authors thank Kenneth Bowman, Eric Jensen and John Bergman for helpful suggestions.

Edited by: A. Engel

\section{References}

Allen, D. R., Stanford, J. L., López-Valverde, M. A., Nakamura, N., Lary, D. J., Douglass, A. R., Cerniglia, M. C., Remedios, J. J., and Taylor, F. W.: Observations of middle atmosphere $\mathrm{CO}$ from the UARS ISMAS during the early northern winter 1991/92, J. Atmos. Sci., 56, 563-583, 1999.

Berthet, G., Esler, J. G., and Haynes, P. H.: A Lagrangian perspective of the tropopause and the ventilation of the lowermost stratosphere, J. Geophys. Res., 112, D18102, doi:10.1029/2006JD008295, 2007.

Browell, E. V., Danielsen, E. F., Ismail, S., Gregory, G.L., and Beck, S. M.: Tropopause fold structure determined from airborne lidar and in situ measurements, J. Geophys. Res., 92, 2112-2120, 1987.

Butchart, N. and Remsberg, E. E.: The area of the stratospheric polar vortex as a diagnostic for tracer transport on an isentropic surface, J. Atmos. Sci., 43, 1319-1339, 1986.

Coy, L., Eckermann, S., and Hoppel, K.: Planetary wave breaking and tropospheric forcing as seen in the stratospheric sudden warming of 2006, J. Atmos. Sci., 66, 495-507, 2009.

Danielsen, E. F.: Stratospheric-tropospheric exchange based on radioactivity, ozone and potential vorticity, J. Atmos. Sci., 25, 502518, 1968.

Engel, A., Bönisch, H., Brunner, D., Fischer, H., Franke, H., Günther, G., Gurk, C., Hegglin, M., Hoor, P., Königstedt, R., Krebsbach, M., Maser, R., Parchatka, U., Peter, T., Schell, D., Schiller, C., Schmidt, U., Spelten, N., Szabo, T., Weers, U., Wernli, H., Wetter, T., and Wirth, V.: Highly resolved observations of trace gases in the lowermost stratosphere and upper troposphere from the Spurt project: an overview, Atmos. Chem. Phys., 6, 283-301, doi:10.5194/acp-6-283-2006, 2006.

Grise, K. M., Thompson, D. W. J., and Birner, T.: A global survey of static stability in the stratosphere and upper troposphere, J. Clim., 23, 2275-2292, doi:10.1175/2009JCLI3369.1, 2010

Haynes, P. and Shuckburgh, E.: Effective diffusivity as a diagnostic of atmospheric transport 2. troposphere and lower stratosphere, J. Geophys. Res., 105, 22795-22810, 2000.

Hegglin, M. I., Brunner, D., Peter, T., Hoor, P., Fischer, H., Staehelin, J., Krebsbach, M., Schiller, C., Parchatka, U., and Weers, U.: Measurements of $\mathrm{NO}, \mathrm{NO}_{\mathrm{y}}, \mathrm{N}_{2} \mathrm{O}$, and $\mathrm{O}_{3}$ during SPURT: implications for transport and chemistry in the lowermost stratosphere, Atmos. Chem. Phys., 6, 1331-1350, doi:10.5194/acp-61331-2006, 2006.

Homeyer, C. R., Bowman, K. P., Pan, L. L., Atlas, E. L., Gao, R.S., and Campos, T. L.: Dynamical and chemical characteristics of tropospheric intrusions observed during START08, J. Geophys. Res., 116, D06111, doi:10.1029/2010JD015098, 2011.

Homeyer, C. R. and Bowman, K. P.: Rossby wavebreaking and transport between the tropics and extratropics above the subtrop- ical jet, J. Altmos. Sci., doi:10.1175/JAS-D-12-0198.1, in press, 2012.

Hoor, P., Gurk, C., Brunner, D., Hegglin, M. I., Wernli, H., and Fischer, H.: Seasonality and extent of extratropical TST derived from in-situ CO measurements during SPURT, Atmos. Chem. Phys., 4, 1427-1442, doi:10.5194/acp-4-1427-2004, 2004.

Hoskins, B. J.: Towards a PV- $\theta$ view of the general circulation, Tellus, Ser. B, 43, 27-35, 1991.

Juckes, M. N.: An annual cycle of long lived stratospheric gases from MIPAS, Atmos. Chem. Phys., 7, 1879-1897, doi:10.5194/acp-7-1879-2007, 2007.

Kanzawa, H., Sugita, T., Nakajima, H., Bodeker, G. E., Oelhaf, H., Stowasser, M., Wetzel, G., Engel, A., Schmidt, U., Levin, I., Toon, G. C., Sen, B., Blavier, J.-F., Aoki, S., Nakazawa, T., Jucks, K. W., Johnson, D. G., Traub, W. A., Camy-Peyret, C., Payan, S., Jeseck, P., Murata, I., Fukunishi, H., von König, M., Bremer, H., Küllmann, H., Park, J. H., Pan, L. L., Yokota, T., Suzuki, M., Shiotani, M., and Sasano, Y.: Validation and data characteristics of nitrous oxide and methane profiles observed by the Improved Limb Atmospheric Spectrometer (ILAS) and processed with the Version 5.20 algorithm, J. Geophys. Res., 108, 8003, doi:10.1029/2002JD002458, 2003.

Kinnison, D. E., Brasseur, G. P., Walters, S., Garcia, R. R., Marsh, D. R., Sassi, F., Harvey, V. L., Randall, C. E., Emmons, L., Lamarque, J. F., Hess, P., Orlando, J. J., Tie, X. X., Randel, W., Pan, L. L., Gettelman, A., Granier, C., Diehl, T., Niemeier, U., and Simmons, A. J.: Sensitivity of chemical tracers to meteorological parameters in the MOZART-3 chemical transport model, J. Geophys. Res., 112, D20302, doi:10.1029/2006JD007879, 2007.

Kunz, A., Konopka, P., Müller, R., and Pan, L. L.: Dynamical tropopause based on isentropic potential vorticity gradients, J. Geophys. Res., 116, D01110, doi:10.1029/2010JD014343, 2011a.

Kunz, A., Pan, L. L., Konopka, P., Kinnison, D. E., and Tilmes, S.: Chemical and dynamical discontinuity at the extratropical tropopause based on START08 and WACCM analyses, J. Geophys. Res., 116, D24302, doi:10.1029/2011JD016686, $2011 \mathrm{~b}$.

Lait, L. R., Schoeberl, M. R., Newman, P. A., Proffitt, M. H., Loewenstein, M., Podolske, J. R., Strahan, S. E., Chan, K. R., Gary, B., Margitan, J. J., Browell, E., McCormick, M. P., and Torres, A.: Reconstruction of $\mathrm{O}_{3}$ and $\mathrm{N}_{2} \mathrm{O}$ fields from ER-2, DC-8, and balloon observations, Geophys. Res. Lett., 17(4), 521-524, 1990.

Lamarque, J.-F., Emmons, L. K., Hess, P. G., Kinnison, D. E., Tilmes, S., Vitt, F., Heald, C. L., Holland, E. A., Lauritzen, P. H., Neu, J., Orlando, J. J., Rasch, P. J., and Tyndall, G. K.: CAM-chem: description and evaluation of interactive atmospheric chemistry in the Community Earth System Model, Geosci. Model Dev., 5, 369-411, doi:10.5194/gmd-5-369-2012, 2012.

Manney, G. L., Hegglin, M. I., Daffer, W. H., Santee, M. L., Ray, E. A., Pawson, S., Schwartz, M. J., Boone, C. D., Froidevaux, L., Livesey, N. J., Read, W. G., and Walker, K. A.: Jet characterization in the upper troposphere/lower stratosphere (UTLS): applications to climatology and transport studies, Atmos. Chem. Phys., 11, 6115-6137, doi:10.5194/acp-11-6115-2011, 2011

Manney, G. L., Michelsen, H. A., Santee, M. L., Gunson, M. R., Irion. F. W., Roche, A. E., and Livesey, N. J.: Polar vortex dynam- 
ics during spring and fall diagnosed using trace gas observations from the Atmospheric Trace Molecule Spectroscopy instrument, J. Geophys. Res., 104, 18841-18866, 1999.

Manney, G. L., Zurek, R. W., Gelman, M. E., Miller, A. J., and Nagatani, R.: The anomalous arctic lower stratospheric polar vortex of 1992-1993, Geophys. Res. Lett., 21, 2405-2408, 1994.

McIntyre, M. E. and Palmer, T. N. : Breaking planetary waves in the stratosphere, Nature, 305, 593-600, 1983.

Neale, R. B., Richter, J., Park, S., Lauritzen, P. H. , Vavrus, S. J., Rasch, P. J., and Zhang, M.: The Mean Climate of the Community Atmosphere Model (CAM4) in Forced SST and Fully Coupled Experiments, J. Clim., in review, 2012.

Novelli, P. C., Masarie, K. A., Lang, P. M., Hall, B. D., Myers, R. C., and Elkins, J. W.: Reanalysis of tropospheric CO trends: Effects of the 1997-1998 wildfires, J. Geophys. Res., 108, 4464, doi:10.1029/2002JD003031, 2003.

Pan, L. L., Bowman, K. P., Atlas, E. L., Wofsy, S. C., Zhang, F., Bresch, J. F., Ridley, B. A., Pittman, J. V., Homeyer, C. R., Romashkin, P., and Cooper, W. A.: The Stratosphere-Troposphere Analyses of Regional Transport 2008 experiment, Bull. Am. Meteorol. Soc., 91, 327-342, 2010.

Pan, L. L., Randel, W. J., Massie, S. T., Kanzawa, H., Sasano, Y., Nakajima, H., Yokota, T., and Sugita, T.: Variability of polar stratospheric water vapor observed by ILAS, J. Geophys. Res., 107, 8214, doi:10.1029/2001JD001164, 2002.

Pan, L. L., Randel, W. J., Gary, B. L., Mahoney, M. J., and Hintsa, E. J.: Definitions and sharpness of the extratropical tropopause: A trace gas perspective, J. Geophys. Res., 109, D23103, doi:10.1029/2004JD004982, 2004.

Pan, L. L., Randel, W. J., Gille, J. C., Hall, W. D., Nardi, B., Massie, S., Yudin, V., Khosravi, R., Konopka, P., and Tarasick, D.: Tropospheric intrusions associated with the secondary tropopause, J. Geophys. Res., 114, D10302, doi:10.1029/2008JD011374, 2009.

Peevey, T. R., Gille, J. C., Randall, C. E., and Kunz, A.: Investigation of double tropopause spatial and temporal global variability utilizing High Resolution Dynamics Limb Sounder temperature observations, J. Geophys. Res., 117, D01105, doi:10.1029/2011JD016443, 2012.

Pittman, J. V., Pan, L. L., Wei, J. C., Irion, F. W., Liu, X., Maddy, E. S., Barnet, C. D., Chance, K., and Gao, R.: Evaluation of AIRS, IASI, and OMI ozone profile retrievals in the extratropical tropopause region using in situ aircraft measurements, J. Geophys. Res., 114, D24109, doi:10.1029/2009JD012493, 2009.

Postel, G. A. and Hitchman, M. H.: A climatology of Rossby wave breaking along the subtropical tropopause, J. Atmos. Sci., 56, 359-373, 1999.

Randel, W. J., Seidel, D. J., and Pan, L. L.: Observational characteristics of double tropopauses, J. Geophys. Res., 112, D07309, doi:10.1029/2006JD007904, 2007.

Randel, W. J., Wu, F., Russell, J. M., Roche, A., and Waters, J. W.: Seasonal cycles and QBO variations in stratospheric $\mathrm{CH}_{4}$ and $\mathrm{H}_{2} \mathrm{O}$ observed in UARS HALOE data, J. Atmos. Sci., 55, 163$185,1998$.
Ray, E. A., Rosenlof, K. H., Richard, E., Parrish, D., and Jakoubek, R.: Distributions of ozone in the region of the subtropical jet: An analysis of in situ aircraft measurements, J. Geophys. Res., 109, D08106, doi:10.1029/2003JD004143, 2004.

Schoeberl, M. R., Lait, L. R., Newman, P. A., Martin, R. L., Proffitt, M. H., Hartmann, D. L., Loewenstein, M., Podolske, J., Strahan, S. E., Anderson, J., Chan, K. R., and Gary, B.: Reconstruction of the constituent distribution and trends in the Antarctic polar vortex from ER-2 flight observations. J. Geophys. Res., 94, 16 815-16 846, 1989.

Shapiro, M. Wernli, A., H., Bao, J.-W., Methven, J., Zou, X., Doyle, J. D., Holt, T., Donall-Grell, E., and Neiman, P. J.: A planetaryscale to mesoscale perspective of the life cycles of extratropical cyclones: The bridge between theory and observations, in The Life Cycles of Extratropical Cyclones, edited by S. Grønås and M. A. Shapiro, 139-185, Am. Meteorol. Soc., Boston, Mass., 1999.

SPARC CCMVal: Report on the Evaluation of Chemistry-Climate Models, edited by: Eyring, V., Shepherd, T. G., and Waugh, D. W., SPARC Report No. 5, WCRP-132, WMO/TD- No. 1526, available at: www.sparc-climate.org, 2010.

Sprenger, M. and Wernli, H.: A Northern Hemispheric climatology of cross-tropopause exchange for the ERA15 time period (19791993), J. Geophys. Res., 108, 8521, doi:10.1029/2002JD002636, 2003.

Sprenger, M., Wernli, H., and Bourqui, M.: StratosphereTroposphere Exchange and Its Relation to Potential Vorticity Streamers and Cutoffs near the Extratropical Tropopause. J. Atmos. Sci., 64, 1587-1602, 2007.

Strahan, S. E., Duncan, B. N., and Hoor, P.: Observationally derived transport diagnostics for the lowermost stratosphere and their application to the GMI chemistry and transport model, Atmos. Chem. Phys., 7, 2435-2445, doi:10.5194/acp-7-2435-2007, 2007.

Tilmes, S., Pan, L. L., Hoor, P., Atlas, E., Avery, M. A., Campos, T., Christensen, L. E., Diskin, G. S., Gao, R.-S., Herman, R. L., Hintsa, E. J., Loewenstein, M., Lopez, J., Paige, M. E., Pittman, J. V., Podolske, J. R., Proffitt, M. R., Sachse, G. W., Schiller, C., Schlager, H., Smith, J., Spelten, N., Webster, C., Weinheimer, A., and Zondlo, M. A.: An aircraft-based upper troposphere and lower stratosphere $\mathrm{O}_{3}, \mathrm{CO}$, and $\mathrm{H}_{2} \mathrm{O}$ climatology for the Northern Hemisphere, J. Geophys. Res., 115, D14303, doi:10.1029/2009JD012731, 2010.

Tomikawa, Y., Nishimura, Y., and Yamanouchi, T.: Characteristics of tropopause and tropopause inversion layer in the polar region, SOLA, 5, 141-144, doi:10.2151/sola.2009-036, 2009.

Wernli, H. and Sprenger, M.: Identification and ERA-15 Climatology of Potential Vorticity Streamers and Cutoffs near the Extratropical Tropopause, J. Atmos. Sci., 64, 1569-1586 2007. 